\title{
ON DETERMINING HOW IMPORTANT IT IS WHETHER OR NOT THERE IS A GOD
}

\author{
T. J. MAWSON \\ University of Oxford
}

\begin{abstract}
Can the issue of how important it is whether or not there is a God be decided prior to deciding whether or not there is a God? In this paper, I explore some difficulties that stand in the way of answering this question in the affirmative and some of the implications of these difficulties for that part of the Philosophy of Religion which concerns itself with assessing arguments for and against the existence of God, the implications for how its importance may best be defended within secular academe.
\end{abstract}

The question that I am addressing in this paper is as follows: Can the issue of how important it is whether or not there is a God be decided prior to deciding whether or not there is a God? In answering this question, our first task must be to obtain clarity over what we mean by importance. A useful distinction to draw at the outset is one between impersonal importance and personal importance. ${ }^{1}$

Suppose, by way of an example, that we're considering how important it is whether or not a relatively small meteorite will hit and kill a given person in five minutes time; this person is in themselves entirely average, i.e. they are not some 'world-historical' individual. This issue has a certain level of importance from what we might roughly think of as 'the point of view of the universe', what I shall call 'impersonal importance.' It has it in virtue of its being the sort of issue that in itself affects the value of the world to a certain extent. If such a meteorite does hit, the world

\footnotetext{
${ }^{1}$ A couple of points by way of forearming the reader against misunderstanding: this is not going to be the distinction between what one might call 'objective' importance (where that is understood as a matter of really having importance) and subjective importance (where that is understood as a matter of appearing to have objective importance) and all cases of impersonal importance might necessarily be person-affecting.
} 
will be a worse place than if it does not but the world is in all other respects the same. It may be that, in addition, the issue of whether or not such a meteorite will hit has what we might call by contrast 'personal importance' for all of us individually - through the principle that no man is an island, entire unto himself; every man's death diminishes every other. It probably has personal importance for the given person's family; and it certainly has personal importance for the given person (unless, perhaps, he or she is indifferent over whether or not he or she lives or is about to die anyway). Be all that as it may, whatever it is that gives this issue the level of impersonal importance that it has must surely give the following issue even more impersonal importance: the issue of whether or not a relatively large meteorite will in five minutes time hit the Earth and kill all its inhabitants. This issue certainly has personal importance for each of us (or at least each of us who isn't indifferent over whether or not he or she lives and isn't about to die anyway). If you are the given person who'd be hit by the first meteorite, then it's arguable that the first issue could have as much personal importance to you as the second. But even if it could in principle, it wouldn't in practice for most because most aren't that narrowly egoistic - we'd prefer to be hit by a meteorite that killed just us (leaving those others we care about alive), rather than be killed by a meteorite that simultaneously killed everyone else. But most of us probably would personally prefer a meteorite to kill several hundred people in a far off country of which we know nothing than for a smaller meteorite to kill us. We would prefer this whilst not being so deluded as to our own grandeur as to think that a small meteorite taking us out would leave the world impersonally a worse place than would the larger one taking out several hundred. ${ }^{2}$

Now obviously whether or not there is a God is an issue which is personally important through being personally interesting to some - professional philosophers of religion, in particular. But it's a fair assumption that the vast majority of those who take a great personal interest in the subject and thus generate for themselves its personal importance only do so because they think that it is impersonally important. And thus a discovery that it wasn't impersonally important would make it considerably less personally interesting to them. It

\footnotetext{
${ }^{2}$ Thus it is that Victorian Englishmen were in the habit of reading with a certain sort of detached excitement - 'Impersonally, this is going to be important; personally, it's not' - articles under newspaper headlines, characteristic of their time and place, such as the following: 'Earthquake Kills Thousands in China. No Englishmen Affected.'
} 
wouldn't immediately make it less personally important to them, but it would with time make it so.

Consider, by way of illustration of all this, the philosopher who is the most personally important to me: me. I've devoted the majority of my working life to considering the issue of whether or not there's a God, but I've done so on the assumption that the issue of whether or not there is a God is a very impersonally important issue. There are other areas of Philosophy I could have specialised in and to which I could even now switch. If the issue of whether or not there's a God is - contrary to my working assumption - not impersonally important, then the fact that it's not impersonally important is very personally important to me. It means that I've spent my working life looking at an issue which is not impersonally important when that's precisely what I wanted not to do and when I could have spent my working life looking at an issue which is impersonally important. (This is assuming some issue in Philosophy is impersonally important; surely there must be one! ${ }^{3}$ ) But of course the discovery that the issue of whether or not there is a God is not an impersonally important issue would, in relatively short order, cease to be of pressing personal importance, as I resultantly shifted my attention to other areas of Philosophy. 'Discovering the subject matter of my earlier work didn't have impersonal importance was very personally important to me', I would soon say, 'in that it redirected me to more impersonally important issues, those on which I now dwell. But that it didn't have impersonal importance isn't of continuing great personal importance; that's not something on which I now dwell'.

So, the interpretation of the question which I'm addressing - 'Can the issue of how important it is whether or not there is a God be decided prior to deciding whether or not there is a God?' - on which we should focus takes the notion of importance in the impersonal way. Taking it in the personal way affords an answer which is too easy - 'Yes, of course; after all, it's just obvious that some people take a great personal interest in the issue, so great an interest that it must be accorded personal importance to them and it's obvious that some such people are theists whilst some are atheists.' It is too easy, but it is also an answer which reveals, on reflection, something cogent to the question as we should interpret it. Most of these people only take a personal interest in the issue (and thus generate this personal importance) because they suppose it to

\footnotetext{
${ }^{3}$ Though see last note.
} 
have great impersonal importance. Thus, if we cannot settle the issue of how impersonally important it is whether or not there's a God in favour of its having great impersonal importance prior to settling the issue of whether or not there is a God, we cannot reasonably hope philosophers will personally interest themselves in the issue regardless of where they fall on the theist-agnostic-atheist spectrum. From henceforth then, when I speak simply of importance I shall mean impersonal importance.

The second task is to understand what it is that fixes the importance of an issue raised by a whether-or-not-hypothesis-A-obtains question. And it seems to me that the correct answer to this is one that pictures the importance of such an issue as a function of the extent to which and manner in which the world would be better or worse if the particular hypothesis under consideration were true relative to how it would be if the hypothesis were false. That is to say, it pictures the importance of the issue as fixed by the differences in value between possible worlds. This manner of thinking seems relatively non-problematic for everyday, contingent, issues. We might reconsider our two meteorites for an example. For another example, we could consider the following. We learn from the newspaper that ours is a world with a certain disease and we ask ourselves how important it is whether or not there's a cure for this disease. To find out the answer, we look into the nearest world in logical space in which there is a cure and see how much better that world is relative to the nearest world in which there's not. The better the first world is than the second, the more important is the issue of whether or not there's a cure. Thus I take it that we'll readily agree that the issue of whether or not there's a cure for a disease that affects relatively few and causes only minor skin blemishes in those whom it does affect is less important than the issue of whether or not there's a cure for cancer. Recently, Guy Kahane has addressed the issue of God's importance in just these terms, telling us that it 'turns on the comparative value of possible worlds; of worlds in which God exists ... and worlds in which He doesn't'.

Now this immediately sounds more problematic than Kahane seems to allow with these comments. ${ }^{5}$ Both theist and atheist will agree that God's existence is either necessary or it is impossible - the theist saying it's

\footnotetext{
${ }^{4}$ Guy Kahane, 'Should We Want God to Exist?', Philosophy and Phenomenological Research, Volume 82, Issue 3 (May 2011), 674-696.

${ }^{5}$ In fairness to him, it should be noted that he does discuss this issue elsewhere in this paper.
} 
necessary; the atheist, it's impossible. ${ }^{6}$ In either case, one of the required sets of comparator worlds is judged to be impossible, i.e. is judged not to exist anywhere in logical space. Thus theist and atheist alike should insist that no comparison of the sort necessary to judge the importance of the issue of whether or not the 'God hypothesis' is true can be made. It looks then as if neither theist nor atheist can say that the issue of whether or not there's a God is an important one as neither theist nor atheist can consistently think that much 'turns on' it, that the world would be a much better or a much worse place depending on whether or not there's a God. Nobody should think that whether or not there's a God is important. That would be, to me anyway, a surprising result and an implausible one; and, in a moment, I'm going to sketch a way in which one may avoid it. But, before I do so, it is worth pausing to note that even if we were to let this conclusion stand, its implications should not be overstated.

This conclusion is compatible with the theist consistently saying that the fact that there is a God is a very important fact. Indeed he or she can say that plausibly it is the most important fact in the actual (and every possible) world, in virtue of its bringing to the actual (and every possible) world various valuable properties. It's just the issue of whether or not there's a God that's not important; it's not important for the comparators necessary for fixing the importance of the 'whether or not issue' are not all available. Similarly, the atheist who accepts this conclusion may say, consistently with that acceptance, that the fact that there's not a God is a very important fact - though it's hard to see why he or she would say the most important fact - in the actual (and every possible) world. He or she can maintain this in virtue of maintaining that it brings to the actual (and every possible) world various valuable (or 'dis-valuable') properties. It's just the issue of whether or not there's a God that's not important, not important as again, he or she must say, the comparators necessary for this sort of issue to be important are not all available.

In other words, one could accept that the issue of whether or not there's a God is not an important one, yet still think that one (but only one) of the more 'partisan' sets of thoughts going on in seminaries and going on in atheist think-tanks and the like is non-problematically directed towards an important fact. And one could still think that the discipline of reflecting on the question of which of these sets is the one that's focused on something important can find a place in secular

\footnotetext{
${ }^{6}$ Of course there are honourable exceptions, but I ignore them in what follows.
} 
academe, agreed across the theist/atheist divide on what one might call 'extrinsic' grounds. In virtue of the extrinsic benefits of thinking about it, both theist and atheist could then agree that thinking about whether or not there's a God may be important without whether or not there is a God being important. But the conclusion that whether or not there's a God isn't important (and through its importance thereby worth thinking about 'intrinsically', as one might put it), even if it leaves all that in place, is still surprising. How best to resist it?

What seems to me the most promising way to seek space within which to say that the issue of whether or not there is a God is important is by taking a view of the modal landscape whereby one construes metaphysically possible worlds as a proper subset of the logically possible. On this view, worlds in which people use the sorts of time-machines that H.G. Wells introduced to science fiction, for example, ${ }^{7}$ are logically possible, but they are not metaphysically possible. (Careful science-fiction writers can write consistent stories about such machines, but the fact that these stories can't be true is more than a contingency of the laws of nature.) So viewed then, when we enter in on the business of comparing the actual world with the closest possible world in which the claim that God exists has the opposite truth value, we should consider ourselves to be crossing the boundary between the metaphysically possible and the metaphysically impossible. But we can consider ourselves not yet thereby to have ventured outside the logically possible; there's still something to be doing the comparing with. How would this play out?

As a theist, I take it that in assessing in this manner how important it is whether or not God exists I must look to the closest world in which God does not exist, which is of course a long way out - past the last metaphysically possible world - and then judge of it whether it is significantly better or worse than the actual world. The border between those worlds which are metaphysically possible and those which are metaphysically impossible (whilst still being logically possible) is rather epistemically vague and, one must fear, arbitrarily drawn. If we put that batch of worries to one side for a moment and continue to have some confidence in our intuitions about what to say about happenings close to the border as responsive to the objective truth of what is happening there, we could see things in following fashion.

${ }^{7}$ Of course one doesn't have to think that this particular thing is an example, just that something is. Another plausible contender for an example would be an actually infinite past. 
As a theist, it's most natural for me to say that in the closest world in which God doesn't exist, nothing else does either because it's a metaphysical necessity that there's a God and it's a metaphysical necessity that everything that's not God depends on God for its existence. So, get rid of the metaphysical necessity that there's a God (that's in itself taking me outside the metaphysically possible, of course), and I'm still left with the metaphysical necessity that anything that's non-God needs God if it's to exist. If so then, when I'm looking in logical space for the nearest world in which there's no God, the first one I'll come to is strict nothingness. Now, if I have the view that value depends for its existence on God, then I'll say that there won't be any value in this world either. It won't, for example, be bad of nothingness that it doesn't have any free creatures in it basking in the beatific vision. If I hold a person-affecting view of value, such that nothing can be good or bad unless there's someone for whom it's good or bad, then I'll again say that the world of nothingness won't have any value in it, for good or bad. But a theist who takes this view of the modal landscape; who holds one of the 'right' meta-ethical views (and there are several that would meet the bill here); and who has one of the right (and there are several again) first-order value judgements, e.g. that nothingness is worse than 'somethingness', can consistently think of the issue of whether or not there's a God as impersonally important.

And the atheist of course will be in a similar position. In order to make the comparison, he or she can adopt this view of the modal territory, locating the nearest world in which there's a God outside the realm of the metaphysically possible, but yet inside the realm of logical possibility. And he or she too can have one of the 'right' meta-ethical views and a suitable first-order value judgement. The worries we put on one side earlier, that the border is epistemically vague and our judgements about it somewhat arbitrary, are cogent. And we may add to them the more basic worry that these metaphysical; meta-ethical; and first-order evaluative views seem 'under-motivated'. But despite all that, this is, I think, the best way to preserve the intuition that whether or not there's a God is an impersonally important issue. Of course the views necessary to make it a way are - most of them anyway - the sorts of things that, if wrong, are wrong of necessity, and thus, if they are wrong, it isn't really a way, a fortiori it's not the best way; it's just epistemically a way to those who haven't yet seen that it's not. So, unless you share these views, you should not, for the sake of consistency, after all think that this is a way to make the issue of whether or not there's a God come out as impersonally important. 
Before I close by recapping, I shall say a little bit about what motivated me to think about the problems there might be in determining the importance of the issue of whether or not there is a God prior to determining whether or not there is a God, i.e. what motivated me to ask the question that's been the focus of this paper: Can the issue of how important it is whether or not there is a God be decided prior to deciding whether or not there is a God? And I shall locate some of the implications of the answer that I have given to that question for the discipline of the Philosophy of Religion.

My desire when first thinking about these issues was to come up with an argument that would secure agreement across the theist/atheist divide about how important it is whether or not there's a God. Indeed, I wanted us to be able to reach this agreement and for the agreed verdict to be that the issue of whether or not there's a God is very important. That would have secured that part of the discipline of the Philosophy of Religion that looks at this issue within secular academe. I haven't got what I wanted. First, I established that the issue of whether or not there's a God is only really going to be taken as important by theists and atheists alike if it can be shown to them to be impersonally important. Personal importance (which is easier to establish) just won't do the job, long-term anyway. But, I argued, at least initially it seems that we cannot reach agreement on the issue's impersonal importance across the theist/ atheist divide because neither theist nor atheist can come to any answer (unless the last way I sketched really is a way) as to how important it is. To decide that it's important whether or not A obtains, we have to find a significant value difference between worlds in which $\mathrm{A}$ is true and worlds in which not-A is true, which means we have to conceive of both A worlds and not-A worlds as possible. But theists will think of worlds in which there isn't a God as impossible and atheists will think of worlds in which there is a God as impossible. Neither theist nor atheist then can do the comparison between worlds in which there is a God and worlds in which there isn't, the comparison required of them if they're to judge that whether or not there's a God is an important issue. Nor of course can an agnostic, who'll say of the relevant worlds that whilst they're all epistemically possible to him or her, of course at least one set must really be impossible. As I went on to point out, the implications of this result should not be overstated. Accepting it is consistent with the theist maintaining that it is nevertheless absolutely valuable that there is a God. God's existence brings value, perhaps even all value, into 
the actual world and all possible worlds. It's just that the theist cannot consistently say that it is 'relatively' good that God exists, in that it would have been worse if God hadn't existed. And similarly, mutatis mutandis, for the atheist. The implications of this result then, as I say, should not be overstated; and neither is it clear that we should accept the result.

The view that we can think of the metaphysically possible as a proper subset of the logically possible offers some hope (at least for those epistemically uncertain about its impossibility, if it is impossible) for an alternative answer. It allows both worlds in which there is a God and worlds in which there is not inside logical space and thus allows them to be compared. With this sort of understanding of the modal landscape, one can in principle make the sort of comparison that is a prerequisite to judging that the issue of whether or not there is a God is an impersonally important one. But one needs to adopt in addition other controversial views, about trans-world value, and the right sort of first-order evaluative view. All of this will seem to many 'under-motivated'. Of course, if one has as one's starting point the 'obvious' truth that whether or not there's a God is a very impersonally important issue, one can run this part of the argument in reverse precisely to motivate these views, concluding that the modal landscape and value is as it would need to be to make it come out true that whether or not there's a God is very impersonally important. ${ }^{8}$

So, in short, the answer to the question 'Can the issue of how important it is whether or not there is a God be decided prior to deciding whether or not there is a God?' is 'Yes' only on controversial assumptions and thus one cannot expect in fact to secure agreement on it amongst all theists, agnostics and atheists. One could perhaps hope to get more widespread agreement on another - closely related - issue and hope that agreement on this related issue would be enough to defend that part of the Philosophy of Religion which focuses on whether or not there's a God within secular academe. Even though it cannot be said (without relying on controversial assumptions) that the issue of whether or not there's a God is important, one might hope that it can be said (without such assumptions) that thinking about the issue is important: it's important to think about the issue of whether or not there's a God because thinking about it leads beyond it, to something of importance. One thing one might suppose theist and atheist can readily agree reflection on the issue

${ }^{8}$ Or one could use the argument to put pressure on my assumption that if God exists, His existence is necessary and if $\mathrm{He}$ does not exist, His non-existence is necessary. 
of whether or not there's a God brings people closer to is knowledge of the truth-value of the proposition that there is a God. (Indeed what else could bring one closer to knowledge rather than just true belief?') Thus they can perhaps agree that the Philosophy of Religion facilitates people (perhaps of necessity better than anything else?) in knowing something which they may also maintain is intrinsically worthy of being known. The theist will identify this as the fact that there's a God (or possibly even just identify it as God). The atheist will identify it as the fact that there's not a God. The necessary first-order value judgement - that it's impersonally important that people be brought to know this - seems to me easier for the theist than the atheist. Theists have better (and more universally believed to be so within their community) arguments for the claim that, given theism, it is impersonally important to know the fact that there's a God. They have better arguments than atheists have for the claim that, given atheism, the fact that there's not a God is one it's impersonally important to come to know. So there'll be trouble reaching consensus spanning the theist/atheist divide this way. But then there are other - less troublesome if more mundane - extrinsic benefits of thinking about the issue to which one can point. The Philosophy of Religion hones skills in analytical reasoning; it introduces students to important thinkers; and so forth. Be all that as it may, I confess to finding this way of proceeding somewhat depressing. In particular, I confess to having found the conclusion that writing this paper has driven me to - that it's not impersonally important whether or not there's a God unless various controversial theses are true - somewhat dispiriting; that's certainly not what I'd hoped to show.

I'd hoped to show that all theists and atheists alike, not just ones who were willing to grant various controversial assumptions, could consistently count the issue of whether or not there's a God as very impersonally important. Thus I'd hoped to show that we who engage in this area of the Philosophy of Religion have no need to enter into the tawdry business of 'selling' our discipline on account of the extrinsic benefits it brings. We wouldn't just be left with the activities of seminaries and the like on the one hand and atheist think-tanks and the like on the other, the enterprise of investigating whether or not there's a God being justifiable to the wider body of theists and atheists alike solely

\footnotetext{
${ }^{9}$ Of course controversial assumptions about the nature of knowledge are creeping in here, again making consensus unlikely.
} 
through a consideration of what I've been calling its extrinsic benefits. But this hope has not been vindicated; it has been dashed. I have found what I have found and must reconcile myself to it. And I can do so - as yet only partially - by reflecting as follows. My hopes were based on a confusion (if my argument's right). The so-called 'world' in which it is important whether or not there's a God for theists and atheists alike without what are actually controversial assumptions needing to be true is an impossible world, logically so, i.e. is no world at all. My hoping that ours would turn out to be such a world was a bit like my hoping - as I did in fact hope when the conjecture was first put to me - that ours turns out to be a world where Goldbach's conjecture has a proof. ${ }^{10}$ By my own logic, it can't then be impersonally important whether or not my hope is vindicated; and now I've made that discovery, it will become increasingly personally unimportant to me that my hope is dashed. Or at least that is what I must now hope. ${ }^{11}$

\footnotetext{
${ }^{10} \mathrm{I}$ am assuming that Goldbach's conjecture has no proof.

${ }^{11}$ I am grateful to Brian Leftow, Guy Kahane, Klaas Kraay, and Richard Swinburne, for their comments on a draft of this paper and I am grateful to those attending the 'Ethics and the Challenge of Secularism' conference at Notre Dame for their comments on some of the ideas in it as I presented them there, particularly to the chairperson of my session, Robert Audi. All of these people have improved this paper in many ways. Obviously, many of the points made in this paper apply mutatis mutandis to other metaphysical theses, viz. all those which are held to be necessary.
} 